\title{
REWARDING PERFORMANCE IN CONSTRUCTION
}

\author{
JAMES HARTY \\ Copenhagen School of Design and Technology, Denmark
}

\begin{abstract}
Copenhagen, among many, wants to be the world's first carbon neutral capital in 2025. This is an ambitious plan requiring long-term action, but it is none-the-less realistic. In 2011, Copenhagen had reduced $\mathrm{CO}_{2}$ emissions by $21 \%$ compared to 2005 . At the moment, design decisions can be said to be all about reputation. A design that is seen as "good" enhances your reputation as a designer. In the future designs will be measured against performance. And that performance has a very direct effect on the financial reward you can expect from good design, from commissioning a good designer. Meanwhile, we are placing ever-greater demands on our built environments, and by adding multiple components to our buildings, we increase the risk and probability of errors. The ability to just delete or change something in the model is much easier than with paper drawings. The model also allows better control over buildability, progress, access to solutions and project economy. The technology likely to have the greatest impact on the next few decades has arrived. It's called the Blockchain. Architecture, Engineering and Construction professionals, (AEC) have always struggled to recover the intrinsic value of their labour. Blockchain with its properties of transparency, immutability and consensus validation now offers them an opportunity to develop a "new value proposition" to extract reward not just for their collaborative services that they have provided, but also the intrinsic intangible value of their collaborative professional service over the lifecycle of a building. Blockchain can offer a method of rewarding stakeholders who procure projects that perform better with a running contract, which if it performs pays out and likewise withholds payment for non-compliance.
\end{abstract}

Keywords: Blockchain, BIM.

\section{INTRODUCTION}

Copenhagen's Lord Mayor Frank Jensen wants to rapidly move toward a zero-carbon future [1]. Adrian Malleson, in the RIBA Journal, noted that the UK government's mandate for BIM meant that performance was to the fore and would reap benefits [2]. Don Tapscott saw a move from a passive internet to an active one as signalling the dawn of the Blockchain [3]. Finally, Malachy Mathews sees the Blockchain, interlaced with BIM, as heralding a new paradigm where both the Latham report, "Constructing the team" and the Egan report "Rethinking Construction" can be delivered [4]. This heady mix asks the question, how!

Traditional construction contracts generally are Design-Bid-Build [DBB] where the lowest or most preferential tender is awarded the work. This has been hailed as flawed for many reasons, topmost being that in order to secure the contract, the bid usually has to be the lowest, and that the only remedy to increased revenues comes from shortfalls within the contract, the documentation or the drawings. These are litigiously examined and result in Requests for Information (RFI's) or Change Orders (CO's) resulting in rework, delays and poor workmanship [5].

RFI's usually seek to clarify further information, or to provide information that was not complete at the time of signing the contract. It is good practice to include in this information, the affected parties, dates, any supporting documentation, as it will form a chain of information, creating a matrix to be tracked, answered and distributed appropriately. If this process constitutes a variation it might qualify the relevant party to an extension of time, or a claim against losses or expenses, delaying the completion date and budget if not carefully managed. It becomes a phenomenon in itself [6]. 
BIM can mitigate this process for the better, and various contract forms strive to address these deficiencies. They range from Design and Build (DB) to Integrated Project Deliveries (IPD) and lately; Insurance-Backed Alliancing (IBA) where the whole team makes joint decisions from day one for the benefit of the project [7]. This involves the insurers keeping checks and balances in the form of three new roles. These are the Financial Independent Risk Assurer (FIRA), the Technical Independent Risk Assurer (TIRA) and also an Independent Facilitator (IF). The first checks the cost plan, while the next assesses feasibilities, while the last stops the team reverting to type with adversarial behaviours. Its intellectual position could be said to align with the Latham report of 1994 [8].

This report wished to delight clients by - in Latham's words - promoting openness, co-operation, trust, honesty, commitment and mutual understanding among team members [9]. Incredibly all of these aspirations have remained on the agenda right up until and including today. Finally, he identified and determined that efficiencies, especially in savings of the order of $30 \%$, were possible. In the report, he condemned existing industry practices as being "ineffective, adversarial, fragmented, incapable of delivering for its customers" and "lacking respect for its employees". Even at this early stage, he urged reform in the industry and advocated partnering and collaboration by construction companies. He went on to say:

"'Partnering includes the concepts of teamwork between supplier and client, and of total continuous improvement. It requires openness between the parties, ready acceptance of new ideas, trust and perceived mutual benefit' and 'Partnering arrangements are also beneficial between firms' without becoming 'cosy' (sic)”.

Many would say that BIM is delivering this nirvana and that collaboration is growing and benefitting better construction, but only to a degree, I would argue. There is no commitment to occupation, circular economies or sustainability, especially with regard to carbon. Handover is still seen as the end of the contract, and in this, all responsibilities vaporise shortly after the building is finished and the snagging complete. Increasingly, we are seeing owners/occupiers not taking over the facility but leasing it back from the builder, ensuring that the risk remains with the contractor, safeguarding any building malfunctions, whilst they are in residence. While this is a tendency, it is not the solution either, the risk can be sold on. A better method is needed to deliver the environment we need and deserve. A better method is needed to encourage those providing this environment to perform. And finally, a better method is needed to reward such practices and document them. This is where Blockchain enters the stage offering solutions to all these needs.

\section{BLOCKCHAIN}

In its simplest form, a Blockchain is a series of blocks of information set in a sequence, or linked together, making a record of transactions, as in a ledger. What makes it unique is that it cannot be tampered with and this is for a number of reasons. First and foremost, it has a distributed ledger technology, which means that it replicates the data so that there is not a single source which can be altered or hacked. Secondly, transactions are transparent, which means that there can be no cheating, no lying through omission and no obfuscation through complexity. It is also considered and accountable, meaning it encourages good faith and discourages blame [10].

This can be best explained using the field of accountancy, which relies on managers to swear that their books are in order. Human error is a leading cause of accounting mistakes. Nearly $28 \%$ of professionals reported that people plugged incorrect data into their firm's enterprise system [11]. Little is done to curb accounting fraud due to the growth of complexity involved and lastly, traditional accounting methods often cannot reconcile these new business models [10]. 


\section{LOW MARGIN MENTALITY}

Construction is generally perceived to be fragmented, it is bedevilled with notorious low margins due the traditional tendering process and it often pays twice to correct poor or faulty workmanship [9]. John Egan [5] and Michael Latham [8] correctly cited these evils within construction and identified corrective measures, without incentive or reward [4]. Arup [12] also acknowledged the same problem in their report about Blockchain Technology:

"However, the sector is limited by the existing data processing and exchange methods which remain characterised by analogue methods that support old adversarial behaviours".

Whenever a project is handed over, there is a procurement process that reaches the end of a cycle mentality. Increasingly, there are methods being tried that seek to prolong or engage that contractual agreement, whether it is soft-landings, life-cycle assessment or facilities management. What none of these embrace is unpredictable performance. There is also no incentive to do so, or a reward system in place to encourage better performance.

\section{LITIGATION}

Data has value that the owner wishes to maximise should it be exchanged by recovering the costs of it and increasing its value in the form of a profit. There is no moral incentive to (freely) share data, even if it makes the job easier. Onerous Information and Communications Technology (ICT) contracts, can place burdens on parties in how data is exchanged, and who holds ownership, copyright and intellectual property. Now I am not condemning them, of course not, they have heralded and made the availability of sharing data possible.

The development of smart buildings also has effects on automated systems, intelligent building management, adaptive energy systems, assistive technologies, remote monitoring and the Internet of Things (IoT) allowing feedback to be collected and the data harvested. Considering that the design life of a building may be 50 years or more, ICT in its current form, might become redundant before completion and occupation. This becomes a bigger problem on an urban scale, where major infrastructure programmes will impact on the economy for years, but an ICT product may last only as long as procurement before it becomes obsolete [13]. Insurance-Backed Alliancing addresses this conflict but remains largely passive in an incentive or reward scenario.

\section{NEW VALUE PROPOSITION}

"For the last two decades, the (construction) sector has tried to apply the collaborative mantra. But at the end of the day, when the chips are down, it is the contract that shapes behaviours and outcomes" [12].

Arup also tells us that the solution craves openness, transparency, honesty and immutability. Blockchain offers permanent, secure and valuable transaction methodologies, they add. Don Tapscott sees the difference as stark as that of the internet of information, compared to the internet of value [10]. Arup goes on to describe a Blockchain of circular BIM things. This is a live BIM (model), "whose components could continuously be fed usage data from real building throughout their operation" [12].

Using Levels of Development (LOD's), this is akin to going from LOD-300, to LOD-400 to LOD-500 and/or even LOD-350 in between [14]. LOD-300 is the level of development that broadly defines the designers' requirements. 350 , is the contractors' take on the designer's requirements. 400, then, is what is ordered to be built, while 500 is the "as-built" completed project. Arguably, there should be no changes through these stages, but this is clearly not the case, as can be seen most glaringly in a project like Grenfell Towers in London [15], where the project went through too many iterations from the architect's intentions to 
the completed refurbishment, resulting in disaster. New replacement windows were $150 \mathrm{~mm}$ too short in width to fit the openings, to meet new energy requirements. These gaps were not properly filled out, allowing the fire unabated access to the interiors [16].

Having a ledger to document this process, and having it decentralised makes it transparent. But it does not end there, by having methods to monitor the use of the building and sensors to report this data back to a database means that algorithms can process this information and establish if the building is delivering what was claimed at the design phase, i.e. accountability is introduced to the contractual obligations, which was not there before.

Being able to measure these savings (should they accrue) in energy use, embedded carbon and optimal occupancy, allows for them to be documented and a method of rewarding such endeavours becomes real. A corollary, of this is that once this is realised, then the actors in the design team and construction team, will find ways to improve this new vertical source of income, becoming better at buildability, sustainability with better performing building stock. Thus they become incentivised [4].

\section{INTRINSIC INTANGIBLE VALUE}

So, an intrinsic value has been found - for a previously intangible value - and it is performance-based, which now can be rewarded. Brooklyn Micro-Gird is a community network, sharing excess energy locally, rather than uploading surplus energy to the national grid. This means that it benefits the community both environmentally and economically [14]. Its emphasis is on purchasing locally sourced power, changing the role of the consumer to that of a prosumer [15]. It works quite simply with a request for electricity, which is verified by the network, approved, recorded and entered into a block of data added to the chain. Once the transaction is complete the energy is delivered.

It uses a TransActive Grid smart metering which is a meter installed in each user's house, beside the distribution box and the domestic fuse box. If a household produces an energy surplus, either through solar power or whatever, the demand is calculated through a token system with no intermediary required. Buyers and sellers use the app to specify their preferences at what price and with whom.

Through Blockchain technology, LO3 developed "Exergy", a permissioned data platform that creates localised marketplaces for transacting energy across existing grid infrastructures through Peer to Peer (P2P) prosumers. Through the Micro-Grid, it is transacted locally, creating more efficient, resilient and sustainable communities. It has a Distributed System Operator (DSO), which has access to building management systems, and using price as a proxy it manages energy use, load balancing demand response at negotiated rates. When an electric vehicle has a surplus of energy, it can be available for purchase on the network. The Micro-Grid can also act as a back-up in power outages.

\section{REWARDING PERFORMANCE}

Coen van Oostrom, a developer in The Netherlands, wanted to create the world's best sustainable building, according to the BREEAM rating method [16]. BREEAM measures sustainable value in a series of categories, ranging from; energy, health and wellbeing, innovation, land use, materials, management, pollution, transport, waste and water [17]. Previously he claims, there was a building in London, which reached a 96\% rating.

His client, a well-known firm; Deloitte and the building The Edge, are situated in Amsterdam. It has over 32,000 sensors measuring occupancy, lighting, temperature and air quality, and is connected to your smartphone via an app, so that it can see who is where and when. This means that they could reduce 4,000 workspaces to 2,000, based on your schedule, ranging from sitting-desk, standing-desk, work-booth, meeting-room, balcony-seat 
or concentration-room. It also knows your preference for light and temperature, and it tweaks the environment accordingly [18].

They achieved 95\% through their methods, and upon inquiry found out that to get the extra credits that something innovative was needed. They talked to Siemens and General Electric, but it was Phillips who had a new system called "Light over the Ethernet" or PoE ("Power over the Ethernet", now), which did not use normal power cabling but rather the ethernet [19]. The significance of this is that while the cable supplied power to the fitting, it became a two-way street, which also allowed the fitting to be monitored, (when it was on, for how long, etc...) to meet sustainable goals for optimisation and productivity. This brought the rating up to $98 \%$ and officially the world's best sustainable building.

At the end of the TED Talk, van Oostrom, pointed towards smart-cities and talked about being off-grid and sharing excess energy, but without mentioning how. Blockchain could have provided a structure to implement this. Brooklyn Micro-Grid does just that [14].

\section{CONCLUSION}

Smart contracts will be one of the most fundamental and disruptive innovations [12]. There are no middle men, and it is effectively executed, once pre-defined conditions are met. They lead to faster settlements and are very accurate. Risks are lessened and costs are reduced because there is no reliance on third parties, especially with legal costs and dispute resolutions. As the Big-Data aspect increases not only will the construction branch improve, but society in general, will appreciate the scalability and maturity of the technology.

It will improve the supply chain with its track and trace capabilities, and this will improve the disparity between LOD's 300-500, as discussed earlier. Given that buildings impact $37 \%$ of primal energy use, $38 \%$ of all carbon dioxide emissions [20], a new mindset is required to challenge the climate emergency. Bringing BIM and the Blockchain together, enables an entirely new paradigm for building data collection leading to truly live BIM (models). This extends the modelling to the circular economy. BIM currently integrates $3 \mathrm{D}$ with $4 \mathrm{D}$ and $5 \mathrm{D}$ (geometry to time to resources) and will grow to 6D and 7D (sustainability and performance). $8 \mathrm{D}$ addresses optimisation and this will make Copenhagen's desire to be carbon neutral by 2025 possible.

\section{REFERENCES}

[1] Gerdes, J., Copenhagen's ambitious push to be carbon-neutral by 2025. The Guardian, 12 April 2013.

[2] Malleson, A., Ahead of the game. RIBA Journal, 123, pp. 46-47, 2016.

[3] Tapscott, D., The Blockchain will Change EVERYTHING!, 2016. https://www.youtube.com/watch?v=yK6Ldefgbl0. Accessed on: 6 Mar. 2019.

[4] BIM+Blockchain: A solution to the trust problem in collaboration? CITA BIM Gathering, 23-24 November, Croke Park, Ireland, 2017.

[5] Egan, J., Rethinking construction. The report of the Construction Task Force, 1998.

[6] Aibinu, A.A., Carter, S., Francis, V. \& Serra, P.V., Necessary evils: Controlling Requests for Information [RFIs] to reduce cost and improve margins. Construction Research and Innovation, 9(4), pp. 103-108, 2018.

[7] Thompson, M., IPI not PII for realistic collaboration. RIBA Journal, 126, pp. 49-50, 2019.

[8] Latham, M., Constructing the team. The final report of the government/industry review of procurement and contractual arrangements in the UK construction industry. Turner \& Townsend News, 1994. 
[9] Harty, J., The Impact of Digitalisation on the Management Role of Architectural Technology, 2012.

[10] Tapscott, D., Blockchain Revolution, Penguin Random House: UK, 2016.

[11] Berry, K., Human errors: The top corporate tax and accounting mistakes, 2015. https://www.accountingweb.com/aa/auditing/human-errors-the-top-corporate-taxand-accounting-mistakes. Accessed on: 10 Mar. 2019.

[12] Kinnaird, C. \& Geipel, M., Blockchain Technology How the Inventions Behind Bitcoin are Enabling a Network of Trust for the Built Environment, Arup, 2017.

[13] Designing Buildings Wiki, Information and communications technology in construction, 2019. https://www.designingbuildings.co.uk/wiki/Information_and_ communications_technology_in_construction. Accessed on: 10 Jun. 2019.

[14] BIM-FORUM. Level of development specification guide, 2017.

[15] Moore-Bick, S.M., Grenfell Tower Inquiry, 2019. https://www.grenfelltowerinquiry.org.uk/. Accessed on: 11 Jun. 2019.

[16] Barratt, L., Grenfell council was warned about gaps in windows by resident of flat where fire began, 2018, https://www.insidehousing.co.uk/news/news/grenfellcouncil-was-warned-about-gaps-in-windows-by-resident-of-flat-where-fire-began56882. Accessed on: 13 Jun. 2019.

[17] Brooklyn Energy, Brooklyn Micro-Grid, 2019. https://www.brooklyn.energy/. Accessed on: 12 Jun. 2019.

[18] Prentice, D., Blockchain for the Renewable Energy Industry, 2018.

[19] van Oostrom, C., Smart Cities: How technology will change our buildings, 2016. https://youtu.be/hT4ZsaZsEgc. Accessed on: 12 Jun. 2019.

[20] BREEAM. BREEAM Category Issues and Aims, 2019. https://www.breeam.com/discover/how-breeam-certification-works/. Accessed on: 12 Jun. 2019.

[21] Randall, T., The Smartest Building in the World Inside the connected future of architecture, 2015. https://www.bloomberg.com/features/2015-the-edge-the-worldsgreenest-building/. Accessed on: 12 Jun. 2019.

[22] Philips. Philips' New Intelligent Connected Lighting System, 2019. https://youtu.be/1ZYJ4wYGajA. Accessed on: 13 Jun. 2019.

[23] Carroon, J., Sustainable Preservation: Greening Existing Buildings, Wiley: USA, 2010. 